\title{
Progressive Fracture of Fiber Composite Build-Up Structures
}

\author{
PASCAL K. Gotsis* AND C. C. Chamis** \\ National Aeronautics and Space Administration \\ Lewis Research Center \\ Cleveland, $\mathrm{OH} 44135$ \\ LEVON MinnETyan $†$ \\ Department of Civil and Environmental Engineering \\ Clarkson University \\ Potsdam, NY 13699-5710
}

\begin{abstract}
Damage progression and fracture of built-up composite structures is evaluated by using computational simulation. The objective is to examine the behavior and response of a stiffened composite $(0 / \pm 45 / 90)_{-6}$ laminate panel by simulating the damage initiation, growth, accumulation, progression and propagation to structural collapse. An integrated computer code (CODSTRAN was augmented for the simulation of the progressive damage and fracture of built-up composite structures under mechanical loading. Results show that damage initiation and progression to have significant effect on the structural response. Influence of the type of loading is investigated on the damage initiation, propagation and final fracture of the build-up composite panel.
\end{abstract}

KEY WORDS: laminated thin shells; laminated cylinders; composite structures; computational simulation; structural analysis; finite element analysis; damage; degradation; durability: fracture; stiffened panel; structural degradation.

\section{INTRODUCTION}

\begin{abstract}
A IRCRAFT, MARINE AND automotive vehicle industries use extensively stiffened composite panels, because of their low weight and high stiffness and stability features. Design considerations with regard to the durability of stiffened panels require a priori evaluation of damage initiation and propagation mechanisms under expected service loading. Concerns for safety and survivability of critical components require a quantification of the composite structural damage tolerance during overloads. Characteristic flexibilities in the tailoring of

\footnotetext{
*Senior Research Engineer. Structures Division. Member AIAA and author to whom correspondence should be addressed.

** Senior Aeruspace Scientist. Structures Divisimn, Fellıw AlAA

tAssociate Professor.
} 
composite structures make composites more versatile for fulfilling structural design requirements. However, these same design flexibilities render the assessment of composite structural response and durability more complex, prolonging the design and certification process and adding to the cost of the final product. It is difficult to evaluate composite structures because of the complexities in predicting their overall congruity and performance, especially when structural degradation and damage propagation take place. The predictions of damage initiation, damage growth, and propagation to fracture are important in evaluating the load carrying capacity, damage tolerance, safety, and reliability of composite structures. The most effective way to obtain this quantification is through integrated computer codes that couple composite mechanics with structural analysis and damage progression modelling. The COmposite Durability STRuctura ANalysis (CODSTRAN) computer code has been developed for this purpose by integrating and coupling the following disciplines: (1) mechanics of composites, (2) structural analysis (FEM) and (3) damage progression/tracking. CODSTRAN was used to simulate the damage progression in a variety of composite structures such as: stiffened adhesively bonded composite structures [1], adhesively bonded concentric composite cylinders [2], damage progression in bolted composite structures [3], progressive damage and fracture of adhesively bonded pipe joints [4], damage tolerance of composite pressurized shells [5] and [6] and dynamic damage progression of a containment structure hit by an escaping blade [7]. The objective of the present paper is to investigate the response of the stiffened composite panel by computationally simulating using CODSTRAN computer code the damage progression and final fracture of the panel subjected to bending loads.

\section{BRIEF DESCRIPTION OF CODSTRAN}

CODSTRAN is an integrated computer code that was written in FORTRAN 77 computer language for unix operating system at NASA Lewis Research Center. CODSTRAN was developed by coupling the following three modules.

(1) ICAN is a computer code [8] that provides the constituent (fiber and matrix) material properties using an available databank, computes the ply properties and the composite properties (effective properties) of the laminate in a hygrothermal environment. The theory of the code is based in the micromechanics of composites and the classical laminate theory. ICAN has the ability to compute the ply stresses by knowing the stress resultants (force per laminate thickness, where force can be a concentrated load, a bending or a twisting load). In ICAN failure criteria were established Figure 1, for the detection of the ply failures as follows: (a) the maximum stress criterion, in which failure occurs when the individual ply stress $\sigma_{i i j}$ for $i, j=1,2,3$, exceeds the respective ply strength $S_{L i j}$ for $i, j=1,2,3$; and (b) the modified distortion energy criterion, in which the combination of the ply stresses is taken into account. In both criteria the ply stresses are refered to the material axes $1,2,3$, and the direction of the $0^{\circ}$ fibers are along the direction of the material 1-axis. In ICAN the described failure modes of the plies are: failure due to the fiber fracture in tension or in compression; damage due to the matrix fracture in tension or in compression; and damage due to shear fracture. 
- MAXIMUM STRESS FAILURE CRITERION.

THE SIX PLY STRESS COMPONENTS ARE ALONG TIE MATERIAL AXES.

$$
\begin{aligned}
& s_{L 11 C}<\sigma_{L 11}<s_{L 11 T} \\
& s_{L 22 C}<\sigma_{L 22}<s_{L 22 T} \\
& s_{L, 33 C}<\sigma_{L 13}<S_{L 33 T} \\
& s_{L 12(-)}<\sigma_{L 12}<S_{L 12(+)} \\
& S_{L 23(-)}<\sigma_{L 23}<s_{L 23(+)} \\
& S_{L 13(-)}<\sigma_{L 13}<S_{L 13(+)}
\end{aligned}
$$

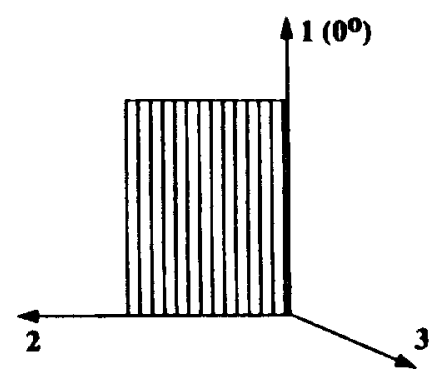

- MDE COMBINED STRESS FAILURE CRITERION.

$$
\begin{aligned}
F=1-\left[\left(\sigma_{L 11 a} / S_{L 11 a}\right)^{2}+\left(\sigma_{L 22 b} / S_{L 22 b}\right)^{2}-K_{L 12 a b}\left(\sigma_{L 11 a} / S_{L 11 a}\right)\left(\sigma_{L .22 b} / S_{L 22 b}\right)\right. \\
\left.+\left(\sigma_{L 12 S} / S_{L 12 S}\right)^{2}\right] .
\end{aligned}
$$

Figure 1. Ply failure criteria.

(2) MHOST is a finite element computer code for the solution of structural analysis problems. The code has the capability to perform linear or nonlinear static and dynamic analysis. MHOST has a library with a variety of elements and for the present work the four node shell element was used. By supplying the boundary conditions, the desire type of analysis, the applied loads and the laminate properties (using ICAN) MHOST performs the structural analysis. In addition MHOST provides the computed stress resultants to ICAN code; and then ICAN computes the developed ply stresses for each ply and checks for ply failure.

(3) A module that keeps track the composite degradation for the entire structure and cooperates with ICAN.

The integrated picture of CODSTRAN simulation cycle is shown in Figure 2. In this figure, from the left side along the clockwise direction the material properties of the constituents (fiber and matrix) are provided by ICAN's database next the ply properties are computed by using the micromechanics theory, and continuing the laminate properties are computed using the laminate theory. These properties in conjunction with the finite element mesh, the loads and the boundary conditions are incorporated into MHOST. MHOST performs the structural analysis and provides the computed stress resultants in ICAN (in the right side of the Figure 2), where ICAN proceeds to compute the ply stresses using the laminate theory and checks for ply failure.

The nonlinear structural analysis is MHOST code is performed in conjunction with an incremental load algorithm. The load is increased in small increments (equilibrium positions). Within each equilibrium position a number of iterations 
(incremental damages) are performed (Figure 3 ). In each iteration, the structure is checked for ply failure. If damages is detected in the structure, the laminate properties of the structure are updated, a new finite element analysis is performed and the above iterations continues until no further damage occurs (equilibrium position). Then, the load is increased and the above procedure is repeated until the final failure of the structure. Following the above procedure we are able to monitor the damage progression, fracture and colapse of the structure.

\section{FIBER COMPOSITE BUILT-UP STRUCTURE}

The investigated structure is a composite panel stiffened by a hat type stringer that is adhesively bond to the skin. The finite element model, shown in Figure 4 , uses a four node shell element. The geometry and the cross section of the stiffened panel with the physical dimensions is shown in Figure 5. The pancl as well as the hat of the structure are made of the same high strength AS-4 graphite libers (Table 1) in a high-modulus, high-strength epoxy matrix HMHS (Table 2). The skin laminate of the structure consists of forty-eight $0.132 \mathrm{~mm}(0.00521 \mathrm{ln}$.) plies resulting in a composite thickness of $6.35 \mathrm{~mm}(0.25 \mathrm{in}$.). The width of the stiffened panel is $330.2 \mathrm{~mm}$ and the length is $279.4 \mathrm{~mm}$. The fiber volume ratio is 0.60 . The laminate configuration is $(0 / \pm 45 / 90)$.6. The $0^{\circ}$ plies are in the axial direction of the stiffener, along the $x$ axis (Figure 4). The stiffener is adhesively bonded to the skin at all surfaces of contact. A negative bending load (with re-

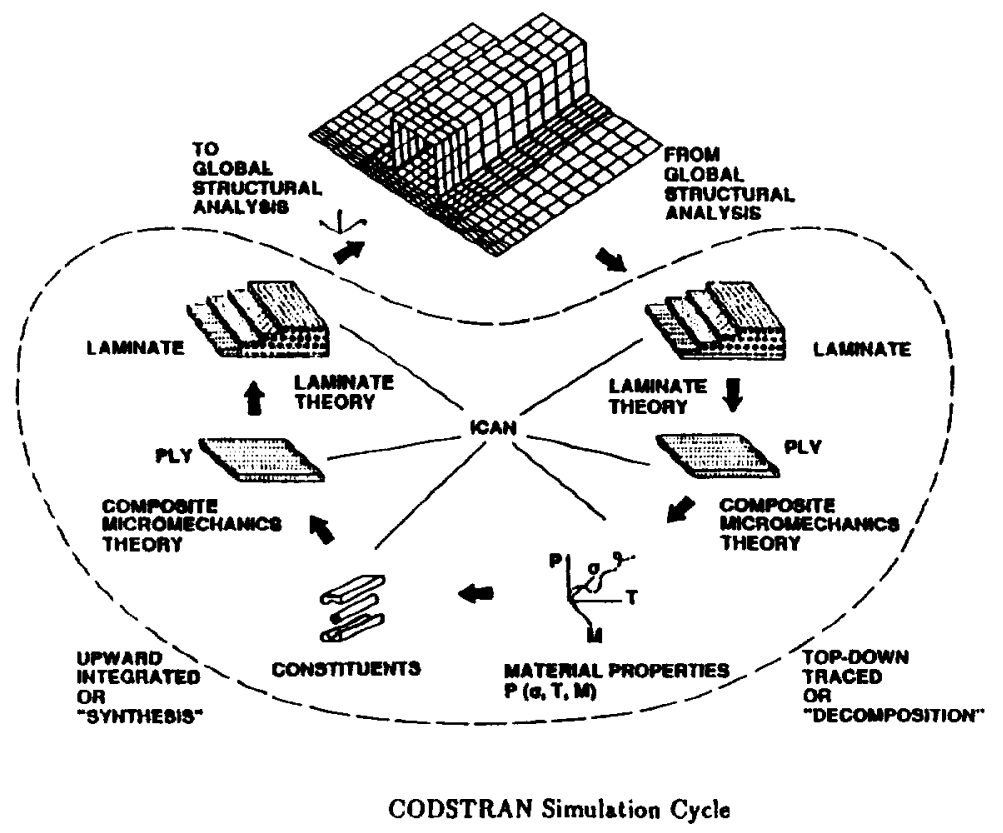

Figure 2. Integrated composite analysis. 


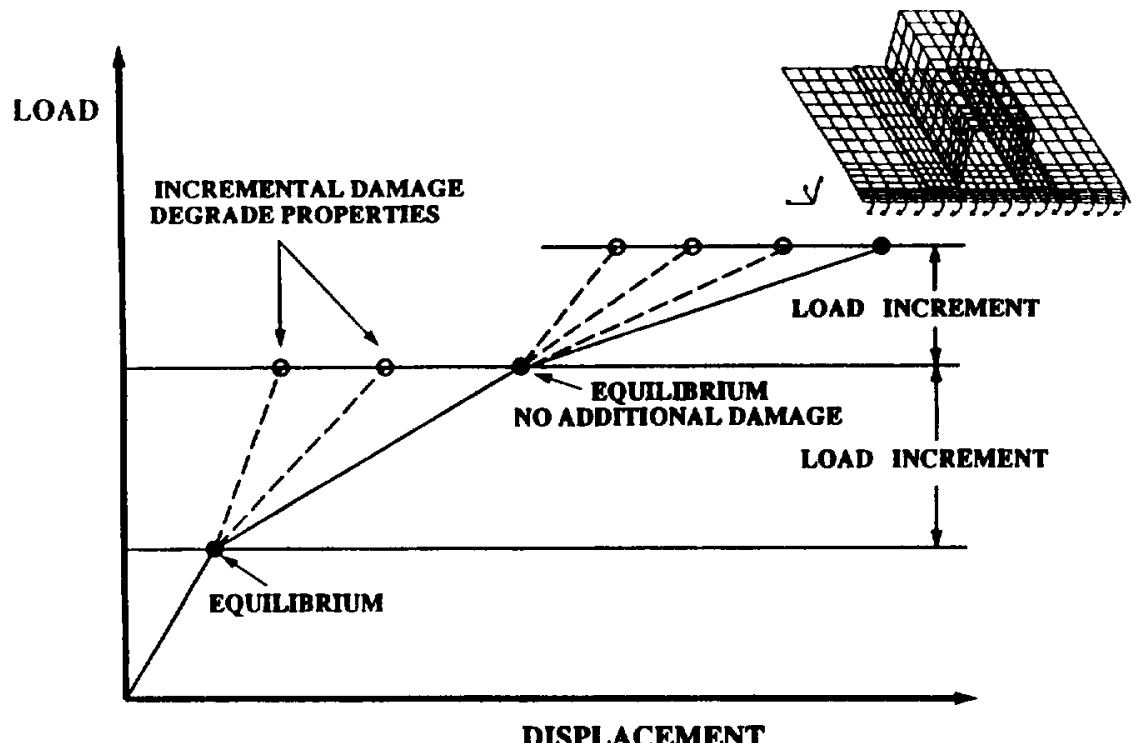

Figure 3. CODSTRAN load incrementation.

spect to $y$-axis) is applied at the free edge of the structure and increased gradually (Figure 4). Damage initiation and progression are monitored as the panel is gradually loaded. For purpose of comparison another case with positive bending load (with respect to $y$-axis) was examined. The damage progression of the stiffened panel as a function of the normalized applied load (maximum catastrophic load

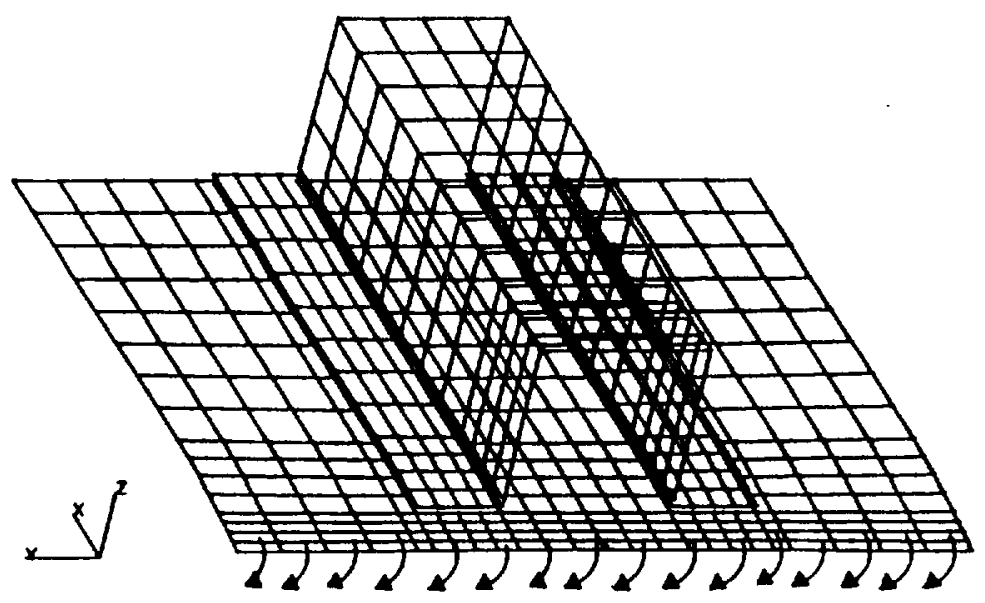

Figure 4. Finite element model. 
GEOMETRY AND MATERIALS
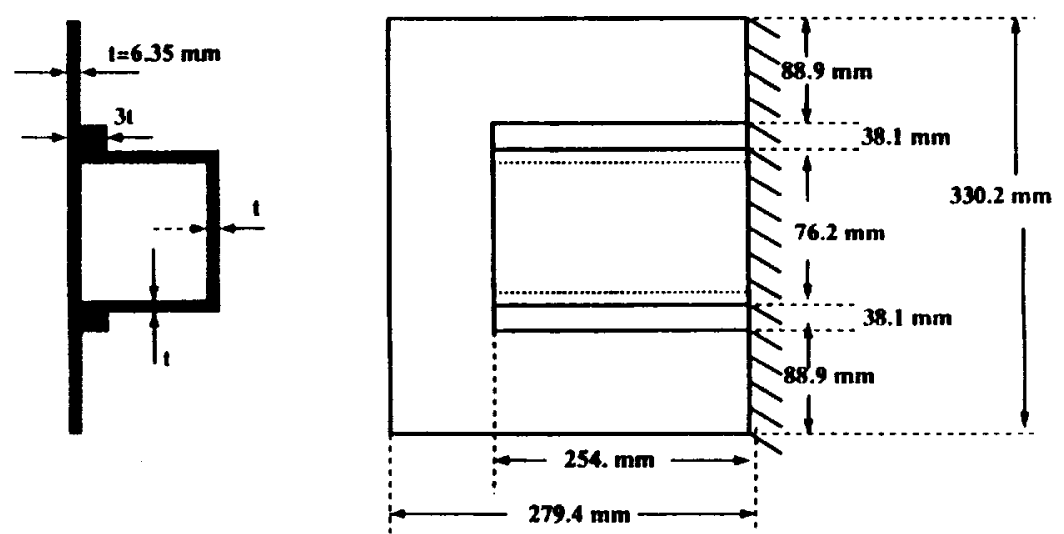

PLATE: AS_4/HMHS, (0/445/90/90/445/0)6 ( 48 PLIES), FVR $=60 \%$

STIFFENER: AS_4/HMHS, $\quad(0 / \pm 45 / 90 / 90 / \pm 45 / 0)_{6} \quad(48$ PLIES $), \quad$ FVK $=60 \%$

Figure 5. Geometry of the built-up structures.

is $2.208 \mathrm{KN}-\mathrm{m}$ due to the positive bending load) is shown in Figure 6. In CODSTRAN damage is defined as the volume of the damaged plies divided by the total volume of the structure. In Figure 6 the depicted points of the damage versus bending load are equilibrium points that we discussed previously. The discussion of the damage initiation and progression follows:

(1) The damage initiation started at 0.4288 of the catastrophic positive bending load ( $2.208 \mathrm{KN}-\mathrm{m}$ or $19.54 \mathrm{Klb}-\mathrm{in})$ for both loading conditions at the front part of the panel, at the contact area of the panel and the stiffener.

In the case of the negative bending load (Figure 7): at the lst load increment, damage occured due to matrix failure in tension (MFT) in the 4th and 5 th $\left(90^{\circ}\right)$ plies while failure happened due to fiber fracture in compression (FFC) in the 48 th $\left(0^{\circ}\right)$ ply. At the 2nd load increment damage occured due to MFT in the 2nd and $3 \mathrm{rd}\left( \pm 45^{\circ}\right)$ plies and at the 12 th and 13 th $\left(90^{\circ}\right)$ plies, and failure due to FFC occured in the 4th and 5 th $\left(90^{\circ}\right)$ plies. At the 3 rd load increment failure due to FFC occured in the 12 th and 13 th $\left(90^{\circ}\right)$ plies.

In the case of the positive bending Figure 8: At the Ist load increment failure due to FFC occured in the Ist $\left(0^{\circ}\right)$ ply, and damage due to MFT occured in the 44th and 45th $\left(90^{\circ}\right)$ plies.

At the 2nd load increment damage due to MFT occured in the 36th and 37th $\left(90^{\circ}\right)$ plies, 43 th and 47 th $\left(-45^{\circ}\right)$ plies and the 46 th $\left(45^{\circ}\right)$ ply and failure due to FFC occured at the 44 th and 45 th $\left(90^{\circ}\right)$ plies. 
Table 1. AA-4 graphite fiber properties.

Number of fibers per end $=10,000$

Fiber diameter $=0.00762 \mathrm{~mm}(0.3 \mathrm{E}-3 \mathrm{in})$

Fiber Density $=4.04 \mathrm{E}-7 \mathrm{Kg} / \mathrm{m}^{3}\left(0.063 \mathrm{lb} / \mathrm{in}^{3}\right)$

Longitudinal normal modulus $=227 \mathrm{GPa}(32.9 \mathrm{E}+6 \mathrm{psi})$

Transverse normal modulus $=13.7 \mathrm{GPa}(1.99 \mathrm{E}+6 \mathrm{psi})$

Poisson's ratio $\left(\nu_{12}\right)=0.2$

Poisson's ratio $\left(\nu_{23}\right)=0.25$

Shear modulus $\left(G_{12}\right)=13.8 \mathrm{GPa}(2 . \mathrm{E}+6 \mathrm{psi})$

Shear modulus $\left(G_{23}\right)=6.9 \mathrm{GPa}(1 . \mathrm{E}+6 \mathrm{psi})$

Longitudinal thermal expansion coefficient $=1 . \mathrm{E}-6 /^{\circ} \mathrm{C}\left(-0.55 \mathrm{E}-6 /{ }^{\circ} \mathrm{F}\right)$

Transverse thermal expansion coefficient $=1 . \mathrm{E}-6 /{ }^{\circ} \mathrm{C}\left(-0.56 \mathrm{E}-6 /{ }^{\circ} \mathrm{F}\right)$

Longitudinal heat conductivity $=43.4 \mathrm{~J}-\mathrm{m} / \mathrm{hr} / \mathrm{m}^{2} /{ }^{\circ} \mathrm{C}$

Transverse heat conductivity $=4.34 \mathrm{~J}-\mathrm{m} / \mathrm{hr} / \mathrm{m}^{2} /{ }^{\circ} \mathrm{C}$

$$
=\left(580 \mathrm{Btu}-\mathrm{in} / \mathrm{hr} / \mathrm{in}^{2} /{ }^{\circ} \mathrm{F}\right)
$$

$=\left(58 \mathrm{Btu}-\mathrm{in} / \mathrm{hr} / \mathrm{in}^{2} /{ }^{\circ} \mathrm{P}\right)$

Heat capacity $=712 \mathrm{~J} / \mathrm{Kg} /{ }^{\circ} \mathrm{C}\left(0.17 \mathrm{Btu} / \mathrm{lb} /{ }^{\circ} \mathrm{F}\right)$

Tensile strength $=3,723 \mathrm{MPa}(540 \mathrm{ksi})$

Compressive strength $=3,351 \mathrm{MPa}$ (486 ksi)

Table 2. HMHS epoxy matrix properties.

Matrix density $=3.4 \mathrm{E}-7 \mathrm{~kg} / \mathrm{m}^{3}\left(0.0457 \mathrm{lb} / \mathrm{in}^{3}\right)$

Normal modulus $=4.27 \mathrm{GPa}(629 \mathrm{Ksi})$

Poisson's ratio $=0.34$

Coefficient of thermal expansion $=0.72 /{ }^{\circ} \mathrm{C}\left(0.4 \mathrm{E}-4 /^{\circ} \mathrm{F}\right)$

Heat conductivity $=1.25 \mathrm{Btu}$-in $/ \mathrm{hr} / \mathrm{in}^{2} /{ }^{\circ} \mathrm{F}$

Heat capacity $=0.25 \mathrm{Btu} / \mathrm{b} /{ }^{\circ} \mathrm{F}$

Tensile strength $=84.8 \mathrm{MPa}(12.3 \mathrm{Ksi})$

Compressive strength $=423 \mathrm{MPa}(61.3 \mathrm{Ksi})$

Shear strength $=148 \mathrm{MPa}(21.4 \mathrm{Ksi})$

Allowable tensile strain $=0.02$

Allowable compressive strain $=0.05$

Allowable shear strain $=0.04$

Allowable torsional strain $=0.04$

Void conductivity $=16.8 \mathrm{~J}-\mathrm{m} / \mathrm{hr}^{\prime} / \mathrm{m}^{2} /{ }^{\circ} \mathrm{C}\left(0.225 \mathrm{Btu}-\mathrm{in} / \mathrm{hr} / \mathrm{in}^{2} /{ }^{\circ} \mathrm{F}\right)$

Glass transition temperature $=216^{\circ} \mathrm{C}\left(420^{\circ} \mathrm{F}\right)$ 


\section{MATERIALS: GRAPHITE/EPOXY $(0 / \pm 45 / 90 / 90 / \pm 45 / 0)_{B}$}

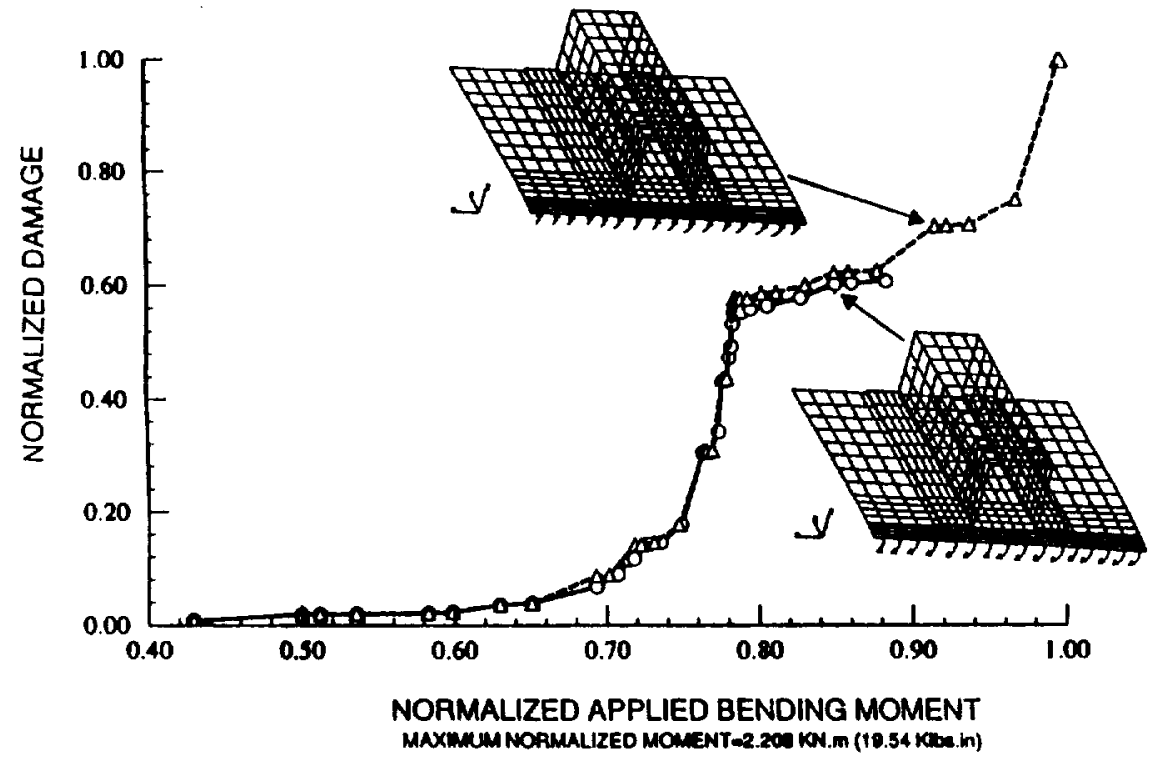

Figure 6. Damage vs. applied load. 


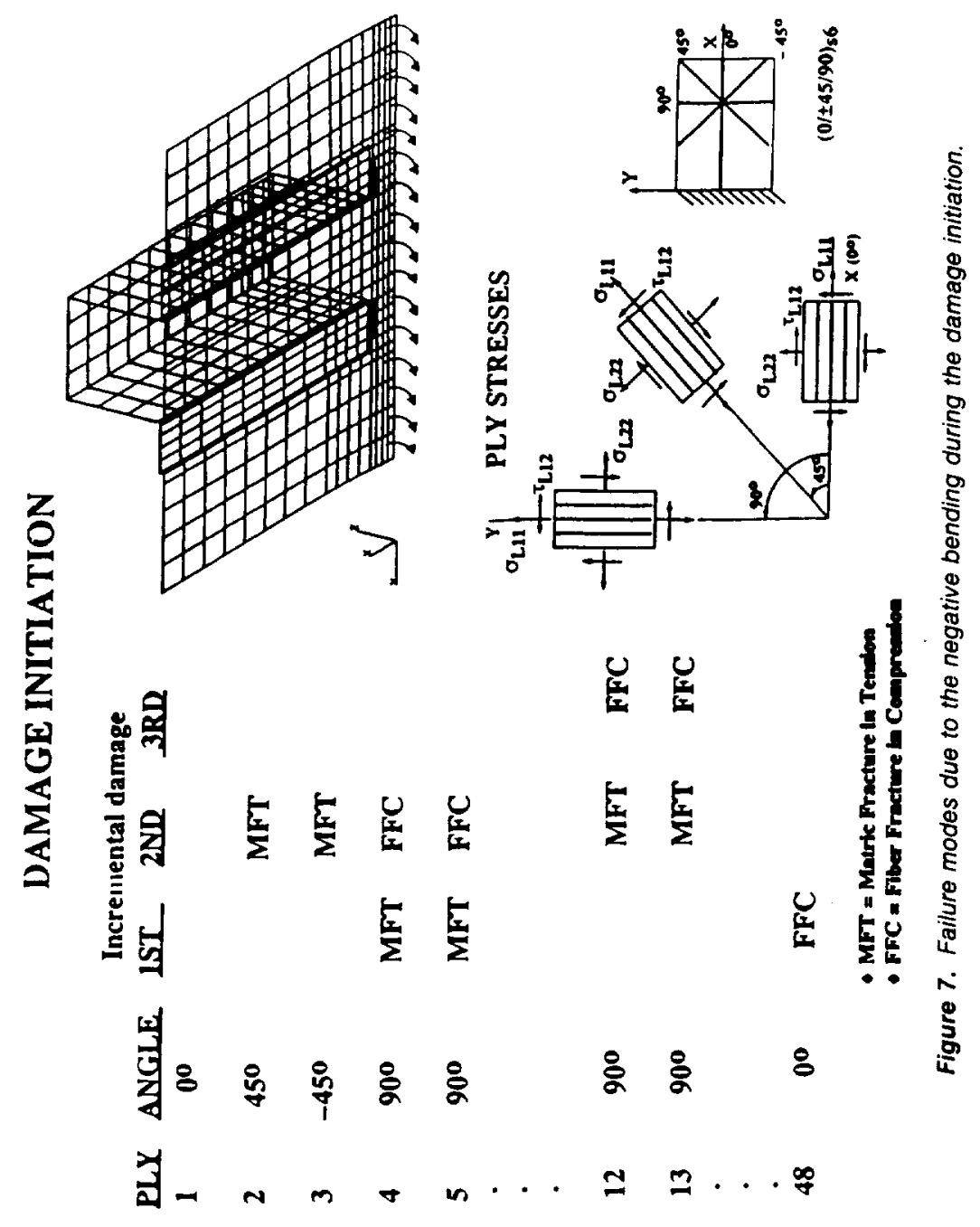




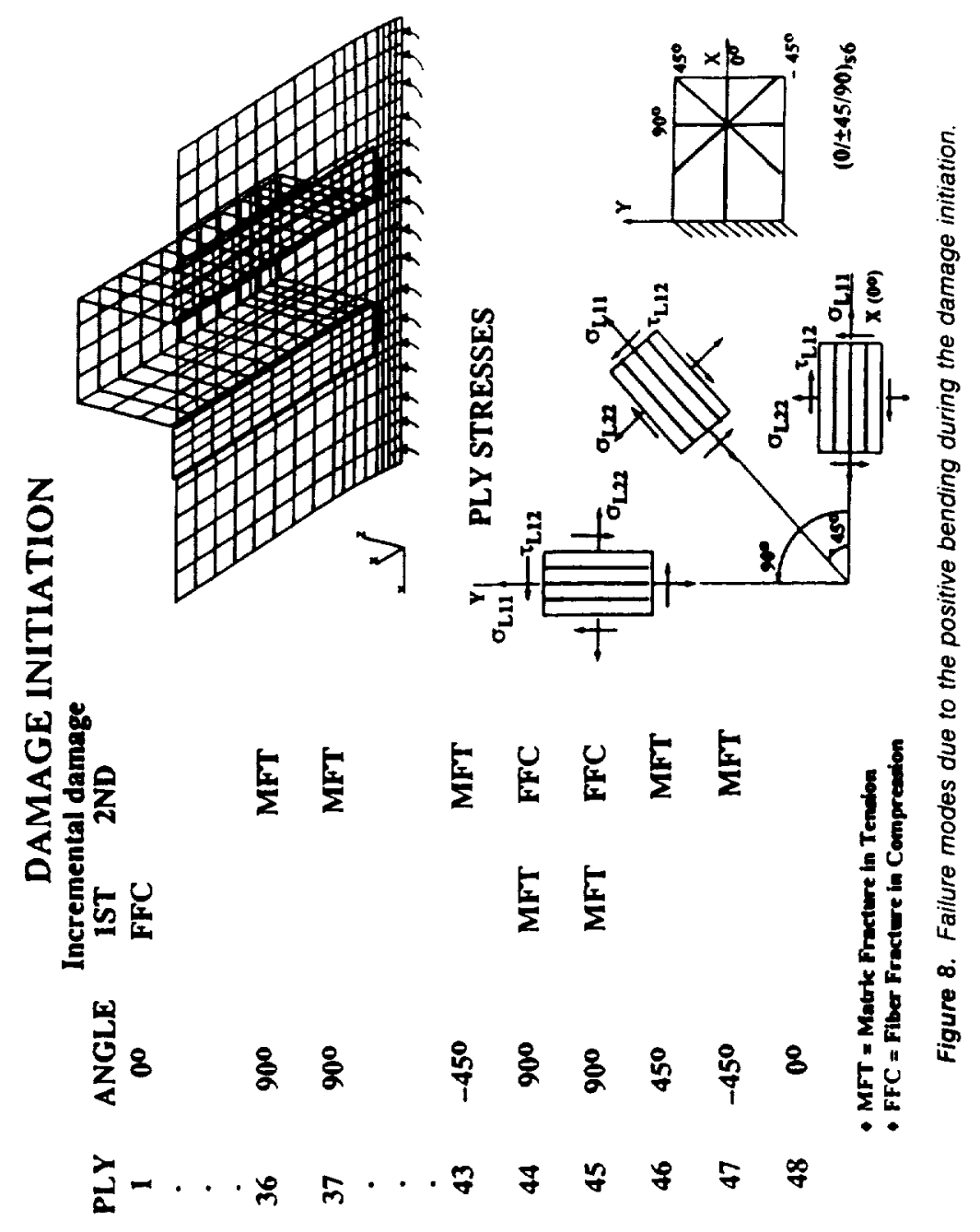


(2) The damage progressed slowly in the front area of the panel until the applied load becomes equal to 0.74 of the catastrophic load. Increasing the load further the damage and the fracture propagates rapidly until the load becomes equal to 0.78 of the catastrophic load.

(c) The catastrophic load for the stiffened panel subjected to the negative bending load was 0.88 of the catastrophic load due to positive bending load. When that load was reached the front part of the panel broke due to the extended fracture of the fibers. The display of the fractured panel subjected to the negative bending load is shown in Figure 9.

For the negative bending, the computed ply stresses were plotted using PATRAN computer code for the damage initiation stage, at the top $\left(0^{\circ}\right)$ and the 3rd $\left(-45^{\circ}\right)$ plies respectively.

At the top ply $\left(0^{\circ}\right)$ (the direction of the fibers are parallel to the $x$-axis) the ply stresses were plotted in the longitudinal (Figure 10) and in the transverse direction of the fibers (Figure 11). In both figures high stresses appeared in front of the panel and at the contact region with the stiffener.

At the 3rd ply $\left(-45^{\circ}\right)$ (the direction of the fibers forms $-45^{\circ}$ with respect to the $x$-axis) the ply stresses were plotted in the longitudinal (Figure 12), and in the transverse direction of the fibers (Figure 13), and also the plane shear stresses (Figure 14). The results show that high stresses occured in front of the panel and at the contact region with the stiffener.

DEFORMED STIFFENED PANEL, AT FRACTURED LOAD, 1.97 KNm (17.29 Klbin)

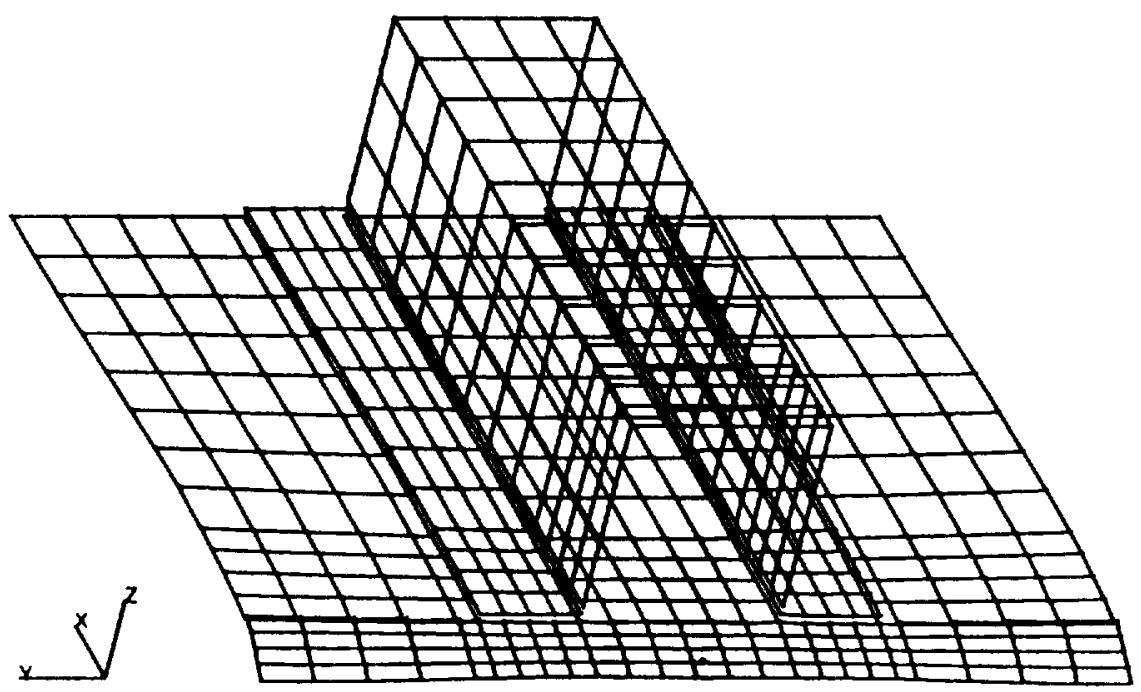

Figure 9. Fractured built-up panel due to the negative bending load. 

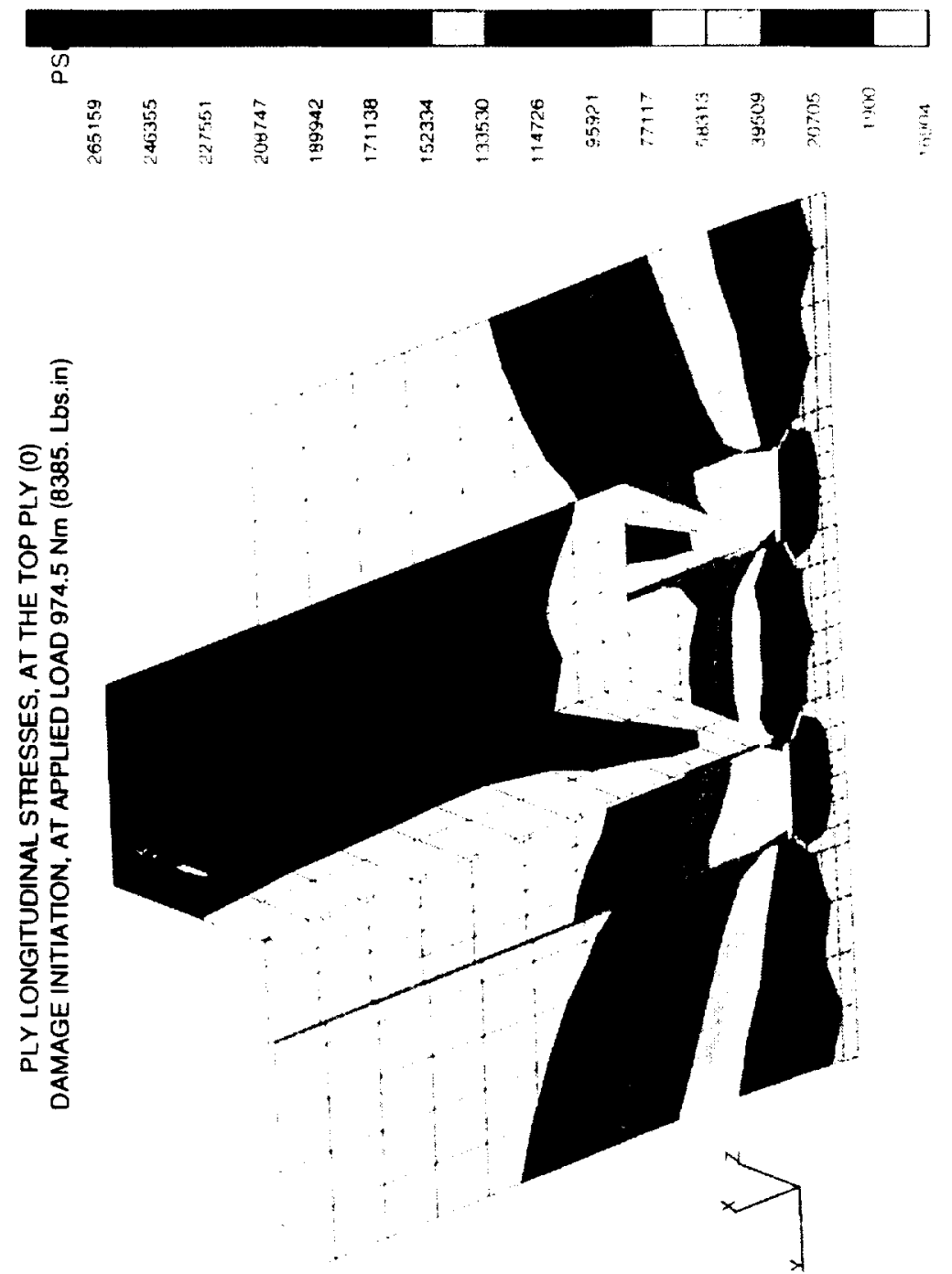


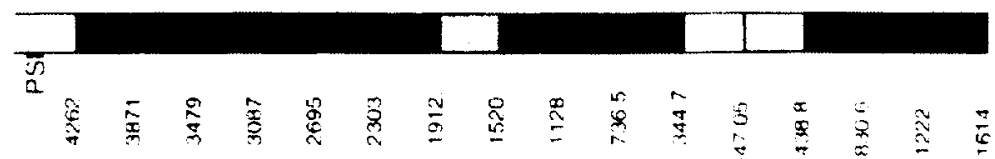

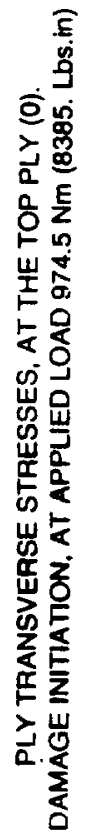

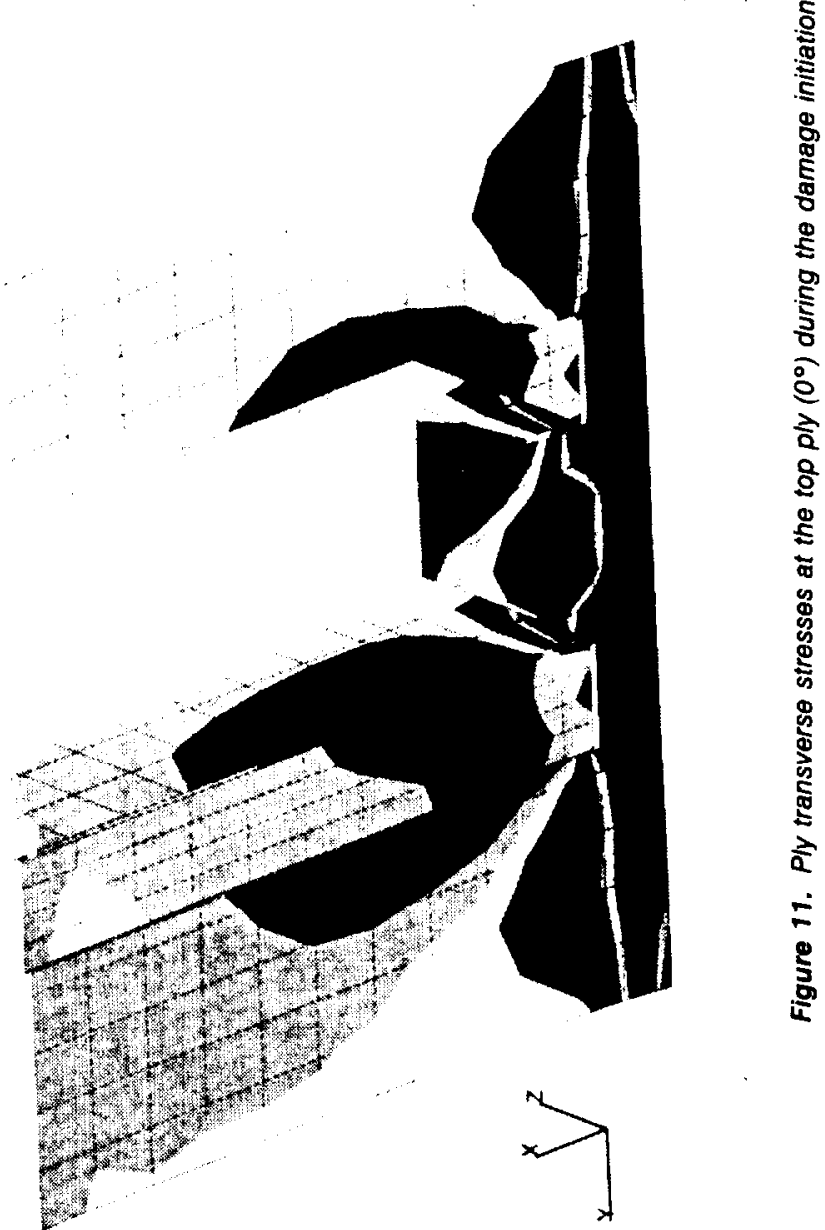




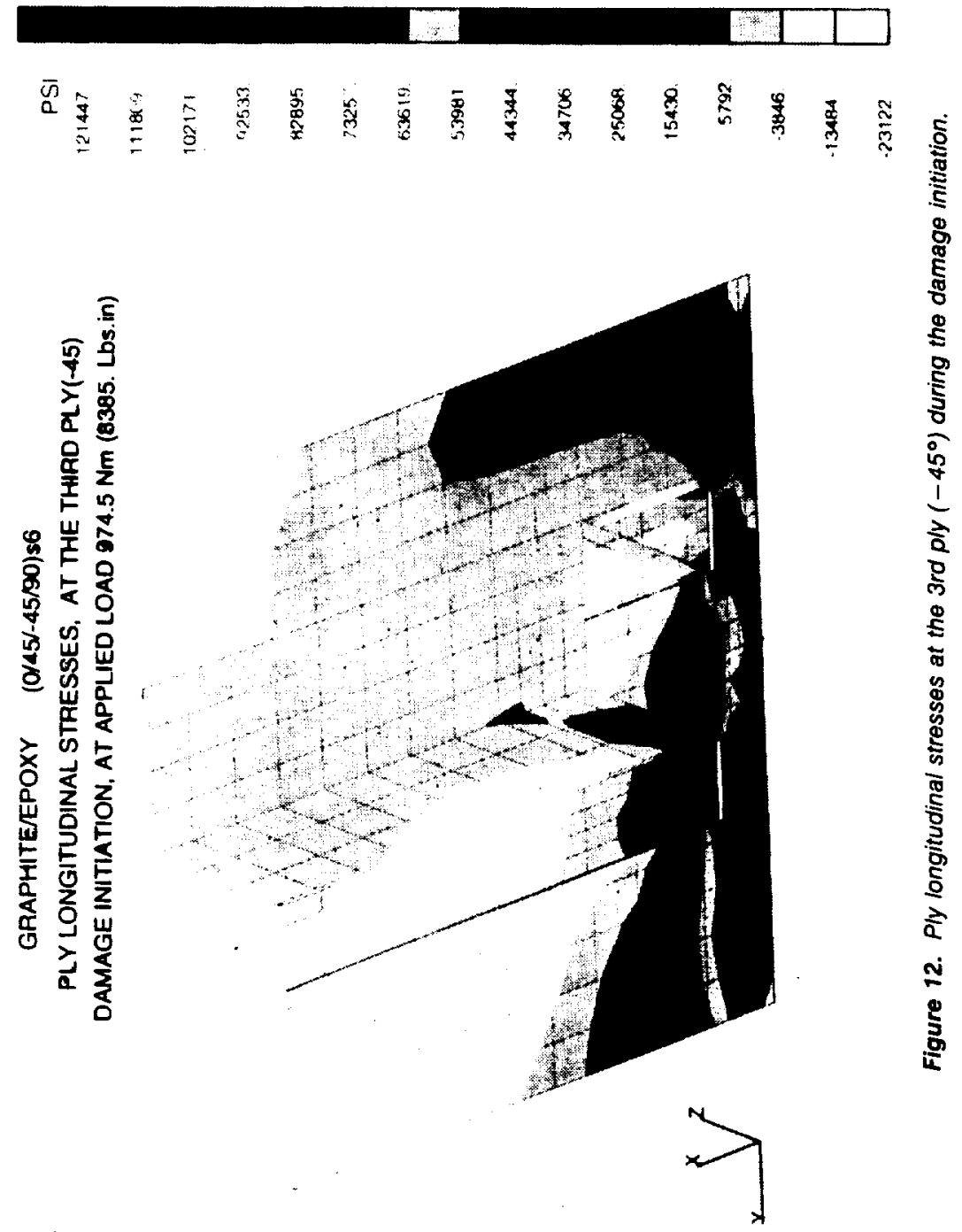



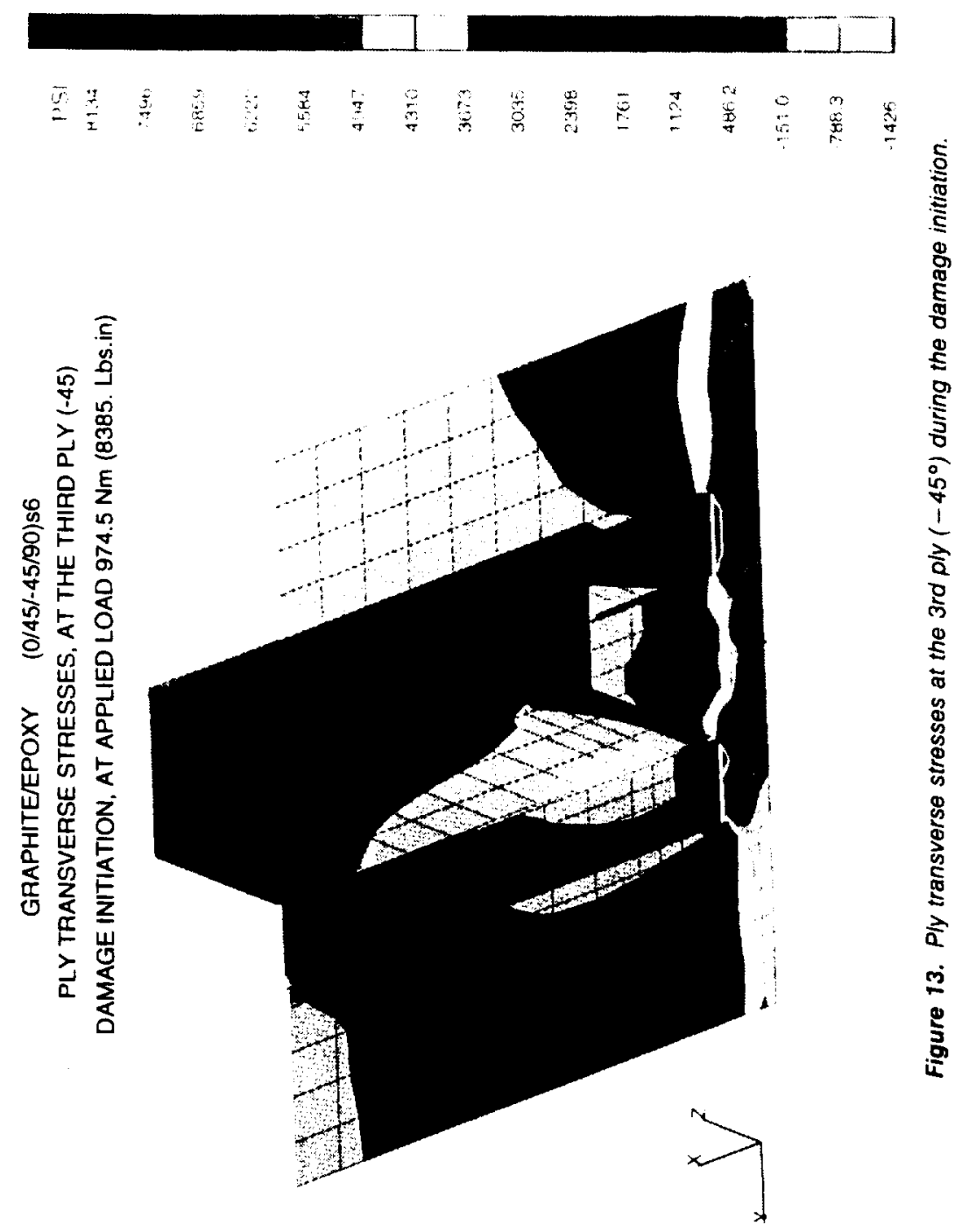

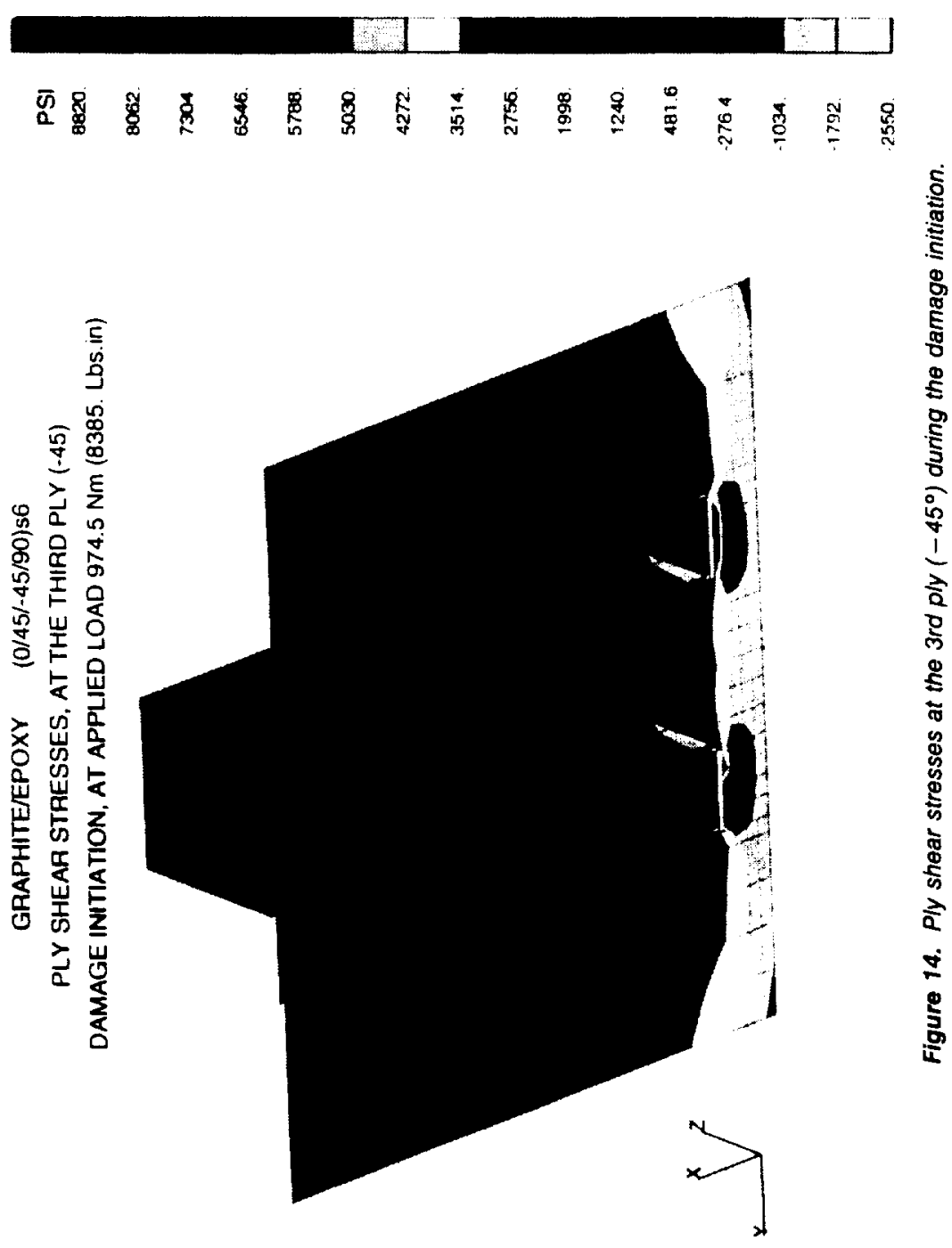


\section{SUMMARY}

The significant results from this investigation in which CODSTRAN (COmposite Durability STRuctural ANalysis) is used to evaluate structural response of a stiffened $(0 / \pm 45 / 90)_{s 6}$ laminate composite panel, considering damage initiation and progression effects, are as follows:

1. Damage initiation started for both bending loads, at applied load equal to 0.4288 of the catastrophic positive bending load at the front part of the panel, at the edge of the panel stiffener. In the case of the negative bending the damage started at the 4 th and 5 th $\left(90^{\circ}\right)$ plies due to matrix fracture in tension and the $48 \mathrm{th}\left(0^{\circ}\right)$ ply due to the fiber fracture in compression. In the case of the positive bending load the damage started at the lst $\left(0^{\circ}\right)$ ply due to the fiber fracture in compression and at the 44 th and 45 th $\left(90^{\circ}\right)$ plies due to the matrix fracture in tension.

2. The damage progressed slowly until the applied load was 0.74 of the catastrophic load, and when the load increased further the damage growth propagaled very rapidly until the load was 0.78 of the catastrophic load.

3. The collapse load due to the negative bending load was 0.88 of the collapse load due to the positive bending load. When that negative bending load was reached the front part of the panel broke due to the extended fracture of the fibers.

\section{REFERENCES}

1. Gotsis, P. K., C. C. Chamis and L. Minnetyan. 1995. "Effect of Combined Loads in the Durability of a Stiffened Adhesively Bonded Composite Structure," Proceedings of the 36th AIAA ASME/ASCE/AHS/ASC Strucrures, Structural Dynamics, and Materials Conference, New Orleans, LA, Part 2, pp. 1083-1092.

2. Minnetyan, L. and P. K. Gotsis. 1995. "Progressive Fracture in Adhesively Bonded Concentric Cylinders," Proceeding of the 40th SAMPE Symposium and Exhibition, Anaheim. California. Vol. 40, book I, pp. 849-860.

3. Chamis, C. C., P. K. Gotsis and L. Minnetyan. 1996. "Progressive Damage and Fracture of Adhesively Bonded Fiber Composite Pipe Joints," Conference \& Exhibitions, 1996: Symposium on Composite Materials, Design and Analysis, Houston, Texas. Proceedings in publication.

4. Chamis, C. C., P. K. Gotsis and L. Minnetyan. 1995. "Damage Progression in Bolted Composite Structures," USAF Structural Integrity Program Conference, San Antonio, Texas.

5. Chamis, C. C., P. K. Gotsis and L. Minnetyan. 1996. "Damage Tolerance of Composite Pressurized Shells," accepted at the 37th AIAA/ASME/ASCE/AHS/ASC Structures, Structural Dynamics, and Materials Conference, Salt Lake City, Utah.

6. Gotsis, P. K., C. C. Chamis and L. Minnetyan. 1996. "Defect Tolerance of Pressurized Fiber Composite Shell Structures," accepted at the 4Ist International SAMPE Symposium and Erhibition, Anaheim, California.

7. Gotsis, P. K., C. C. Chamis and L. Minnetyan. 1996. "Progressive Fracture of Blade Containment Composite Structures," submitted for publication at lith DOD/NASA/FAA Conference on Fibrous Composites in Structural Design, Fort Worth, Texas.

8. Murthy, P. L. N. and C. C. Chamis. 1986. "ICAN (Integrated Composite Analyzer)," Users and Programmers Manual, NASA TP 2515. 


